\title{
ESQUIVANDO AL ESTADO. PRÁCTICAS PRIVADAS EN EL USO DE LOS SERVICIOS DE SALUD ENTRE INMIGRANTES NICARAGÜENSES EN COSTA RICA
}

\author{
SIDESTEPPING THE STATE: PRACTICES OF SOCIAL SERVICE \\ COMMODIFICATION AMONG NICARAGUANS \\ IN COSTA RICA AND NICARAGUA
}

Caitlin E. Fouratt

Koen Voorend

Recibido: 28/01/2019 - Aceptado: 11/03/2019

\begin{abstract}
Resumen
Este artículo evalúa críticamente la relación entre la población migrante y el Estado, en particular la política social pública, tanto en el país de origen como en el país receptor. Se analiza la medida en que las familias migrantes nicaragüenses incorporan la protección social pública en sus estrategias de bienestar a ambos lados del sistema migratorio, Costa Rica-Nicaragua. Basados en dos grupos de datos cualitativos, se encontró que, en ambos lados de la frontera, las personas migrantes y sus familias evidencian prácticas mercantilizadas muy similares de estrategias de bienestar, donde esquivan al Estado y compran servicios en el sector privado.

Palabras clave: migración, remesas, servicio de salud, legalidad, servicio social, burocracia.

Abstract

This paper critically assesses the relationship between migrants and the state, and public social policy, in both sending and receiving country. We analyze the extent to which Nicaraguan migrant families on both sides of the Costa Rica-Nicaragua migration system incorporate public social protection in their welfare strategies. Drawing on two sets of qualitative data, we find that, on both sides of the border, migrants and their families display very similar commodified practices of welfare strategies, side-stepping the state and purchasing services in the private sector.
\end{abstract}

Keywords: migration, remittances, healthcare, legality, social services, bureaucracy. 


\section{Introducción $^{1}$}

Existe una creencia generalizada entre la población costarricense de que las personas nicaragüenses migran al país no solo para encontrar mejores condiciones laborales, sino también para usar los servicios sociales generales que el país ofrece (Bonilla). Además, tres de cada cuatro costarricenses creen que la población migrante nicaragüense compromete la sostenibilidad financiera de tales servicios y que son la causa del deterioro del servicio (Solís). Esta idea de que los servicios sociales son un imán de bienestar para la migración nicaragüense está arraigada no solo en la población en general, sino también entre las personas que diseñan y ejecutan política pública (Voorend y Venegas, 2014).

La polémica sobre la incorporación de las personas nicaragüenses en servicios sociales se basa en varios supuestos: a) que los nicaragüenses establecen una relación con el Estado en su nueva sociedad receptora, b) que ellos reconocen sus derechos sociales y, más específicamente, c) que acceden a los servicios sociales. Sin embargo, a pesar de la retórica política costarricense orientada a la inclusión, las personas inmigrantes nicaragüenses se enfrentan a barreras importantes para la integración, debido a tres factores claves. Primero, los nicaragüenses ya poseen una relación débil con los servicios sociales en su propio país (Martínez y Voorend, 2012a; Martínez y Voorend, 2012b); segundo, la política migratoria de Costa Rica es bastante restrictiva (Voorend, 2016); y tercero, las relaciones laborales en ambos lados de la frontera se caracterizan por su informalidad. Así, las personas migrantes nicaragüenses y sus familias enfrentan varios obstáculos para acceder a los servicios sociales públicos.

En este artículo se analiza la forma en que la población nicaragüense en Costa Rica y sus familias en Nicaragua incluyen la protección social pública en sus estrategias de bienestar. Esta investigación se enfoca específicamente en el acceso a los servicios públicos de salud y a los medicamentos públicos por varias razones importantes. En primer lugar, a diferencia de las pensiones o de la educación básica, la atención médica es requerida durante toda la vida de una persona y, a diferencia de las transferencias familiares y de otros servicios sociales focalizados, es necesaria en cualquier clase social o grupo étnico. En segundo lugar, debido a que la atención médica implica una interacción directa entre las personas migrantes y el Estado, la presencia migrante es más visible en este sector. La reciente crisis financiera en la institución pública de salud del país, la Caja Costarricense de Seguro Social (CCSS o, simplemente, la Caja), ha hecho más controversial los reclamos de las personas migrantes por la atención médica.

Los resultados de este trabajo aclaran cómo, pese al marcado contraste entre la provisión general del servicio de salud de alta calidad de Costa Rica y la mala calidad y cobertura de servicios de salud en Nicaragua, los nicaragüenses evaden al Estado en ambos lados de la frontera y cómo la mercantilización que resulta de este hecho implica que se busca el mercado para el acceso a los servicios de atención médica. 
Por mercantilización se entiende la mayor medida en que las personas recurren al mercado para la suministración de bienes y servicios, por el cual el paciente paga en el momento en que lo necesite para garantizar su bienestar.

Esta mercantilización es el resultado de la exclusión por parte de los servicios sociales públicos en ambos países, la cual apunta a preocupaciones mayores sobre la expansión de los derechos sociales en las sociedades receptoras de inmigrantes y la comercialización de los servicios sociales entre aquellos excluidos del acceso a los bienes públicos. Se encontró que, si bien se accede a los servicios públicos de atención médica, especialmente, para los niños y, a veces, a través de ellos, los adultos a menudo recurren al sector privado para buscar estrategias de atención médica. En Costa Rica, el acceso a la atención médica pública es limitado por mecanismos legales y extralegales, mientras que en Nicaragua los servicios estatales son cualitativamente insuficientes para cubrir a toda la población. Además, en el contexto nicaragüense de pobreza y de informalidad, las remesas desempeñan un papel fundamental en la comprensión de las dinámicas del acceso a los servicios sociales.

Este artículo se estructura de la siguiente forma. Tras ofrecer las secciones de marco teórico y metodológico, se examinan los contextos de las personas inmigrantes nicaragüenses en Costa Rica y sus familias en Nicaragua y las condiciones para su incorporación a los servicios sociales en ambos países. A continuación, se analizan los principales hallazgos de las entrevistas, las cuales muestran cómo la atención médica para las personas migrantes y sus familias a menudo se mercantiliza a través del mercado en lugar de acceder a los servicios sociales públicos en ambos lados de la frontera. La última sección presenta comentarios finales sobre la relación entre migración, exclusión social y el Estado.

\section{Método}

Metodológicamente, este artículo se basa en dos fuentes de datos. La primera se conforma de datos de discusiones de grupos focales, hechas en el marco del estudio de Voorend (2016), específicamente dirigidas a aclarar las medidas y las formas en que las personas migrantes y sus familias incorporan los servicios públicos de atención médica en sus vidas cotidianas. El objetivo de estas discusiones fue comprender cómo la población nicaragüense en Costa Rica utiliza los servicios de salud, en qué medida ellos pueden demandar y acceder a estos servicios y qué tan importantes son los factores sociales, tales como el estatus migratorio, las características del hogar y la inserción laboral, para exigir sus derechos.

Estas discusiones entre grupos focales brindaron información importante sobre el conocimiento que tienen las personas acerca de sus derechos y sobre cuáles factores pueden inhibir el acceso real a estos. En total, entre el 2014 y el 2015, se organizaron ocho discusiones de grupos focales de aproximadamente cuatro a seis participantes, 
para un total de cuarenta y un migrantes nicaragüenses en diferentes partes de Costa Rica. Las áreas se eligieron sobre la base de consideraciones pragmáticas de viabilidad y la disponibilidad de contactos con migrantes o con organizaciones que trabajan con migrantes que podrían facilitar el contacto.

Las personas participantes fueron seleccionadas para maximizar la variación entre sí, con el fin de identificar tendencias generales que trasciendan estas diferencias. Si bien la composición de las discusiones de los grupos focales fue el resultado de la técnica de bola de nieve, en la práctica estaban compuestas por participantes con diferentes estatus migratorios, quienes trabajaron en diferentes sectores y llegaron a Costa Rica en diferentes periodos.

La segunda fuente de datos proviene del estudio etnográfico de Fouratt (2014a), realizado entre el 2009 y el 2012, de familias transnacionales nicaragüenses que viven entre Costa Rica y Nicaragua. Dicho estudio incluyó más de cien entrevistas semiestructuradas en Costa Rica y en Nicaragua, así como la observación participante con migrantes nicaragüenses en Costa Rica y sus familiares en Nicaragua. Los objetivos de este estudio fueron comprender cómo la migración afecta las relaciones familiares y los conceptos de familia y género, y los impactos de la reciente reforma migratoria en Costa Rica. Las entrevistas semiestructuradas abarcaron historias de migración familiar y relaciones familiares, así como prácticas de envío y recepción de remesas, encuentros de migrantes con instituciones estatales y su comprensión de las políticas de inmigración actuales. El acceso a los servicios sociales se discutió en entrevistas directas y en conversaciones informales sobre el estado legal, adaptación e integración en Costa Rica, y el cuidado de los niños en ambos países. El estudio se enfocó, principalmente, en diez familias que viven entre Costa Rica y los departamentos nicaragüenses de Granada, Masaya, Managua, Chinandega y León.

En Costa Rica, todas las personas participantes del estudio eran migrantes nicaragüenses que vivían en el área metropolitana de San José, aunque sus familias vivían en diferentes departamentos de Nicaragua. Mientras que las personas entrevistadas fueron identificadas a través de la técnica bola de nieve, fueron escogidos para reflejar la variación en el estado migratorio, la estructura familiar y el periodo de llegada a Costa Rica.

En el análisis a continuación, las mujeres representan la mayoría de las personas participantes citadas. Esto se debe en parte al resultado de un muestreo etnográfico basado en el "efecto bola de nieve". También señala las formas en que las mujeres actúan como mediadoras entre las instituciones estatales y las familias. Tanto en Costa Rica como en Nicaragua, a menudo son las mujeres quienes cuidan a niños y enfermos, quienes hacen fila en las clínicas y llevan a los niños a citas, y quienes administran las remesas y los presupuestos del hogar.

El presente análisis se basa en los trabajos previos de los autores al observar específicamente las prácticas de acceso a la atención médica en lugar de los canales 
formales o legales para dicho acceso. El trabajo previo de los autores ha analizado en qué medidas y formas las personas migrantes incorporan los servicios sociales en sus estrategias de bienestar, los laberintos burocráticos creados por las nuevas políticas de inmigración y el papel de la ilegalidad en la vida cotidiana de las personas. Este artículo trata de cómo las personas migrantes experimentan estos obstáculos y qué tipo de estrategias emplean para acceder a los servicios. Finalmente, al utilizar ambos conjuntos de datos cualitativos, el análisis incorpora estas estrategias de búsqueda de atención médica en ambos lados de la frontera.

En las páginas siguientes, más que analizar los números o proporcionar análisis legal, este artículo se interesa en prácticas reales de comportamiento de búsqueda de atención médica, especialmente la dinámica y la medida en que los nicaragüenses, en ambos lados de la frontera, usan los servicios de salud públicos versus los privados. Específicamente, se desea conocer cómo las personas migrantes nicaragüenses, en Costa Rica, perciben y enfrentan las limitaciones de la inclusión en los acuerdos de bienestar social público. Asimismo, se desea estudiar en qué medida las remesas y la migración influyen en el acceso de las familias a la atención médica en Nicaragua.

\section{Inclusión social, migración y acceso a la política social}

El carácter universal y solidario del régimen de política social de Costa Rica a menudo es considerado un factor explicativo importante para la inmigración nicaragüense (Bonilla). Tales argumentos están respaldados por la expectativa general en la literatura europea de que los regímenes universales de política social proporcionan mejores condiciones para la integración de las personas inmigrantes (Banting; Faist, 1996; Hjerm; Morissens; Van Hooren; Sainsbury, 2006). En resumen, esta literatura sostiene que las personas inmigrantes en tales Estados disfrutan de más derechos sociales, ya que los ciudadanos también lo hacen.

Sin embargo, las políticas sociales también son los principales mecanismos de exclusión o inclusión dentro de una sociedad (Fischer; Mkandawire). De hecho, una política social fuerte puede funcionar como un arma de doble filo: puede facilitar la incorporación de las personas inmigrantes, pero también puede funcionar como un mecanismo eficiente para el control migratorio y como un factor determinante de la exclusión de migrantes a través de criterios estrictos de elegibilidad (Hollifield). Además, los procesos de discriminación y las formas extrajudiciales de exclusión significan que la ciudadanía civil formal puede ser una condición necesaria, pero no suficiente para el acceso de las personas inmigrantes a los servicios sociales.

Por el contrario, los globalistas creen que los Estados están cada vez más obligados a conceder amplios derechos sociales a las personas migrantes (Favell; Jacobson; Sharma; Soysal). La migración es vista como un caso en que los Estados nación pierden el control (Guiraudon y Lahav). Estos autores argumentan que la 
lógica "desnacionalizante" de la globalización económica conduce a una mayor movilidad capital, financiera y laboral y, de ese modo, disminuye el poder y la importancia del Estado nación. En este escenario, las perspectivas globalistas argumentan que los regímenes internacionales de derechos humanos y la migración desafían la soberanía del Estado nación, induciendo así a una devaluación de la importancia de la ciudadanía (Sassen). La ciudadanía cada vez más se ejerce y se administra transnacionalmente, como resultado del surgimiento de un "régimen internacional de derechos humanos que impide a los Estados-nación decidir quién puede entrar y salir de su territorio" (Guiraudon y Lahav 164) (También se puede consultar Sharma; Soysal). Las agendas de derechos humanos prevalecerían entonces sobre los intentos nacionales de exclusión de los derechos sociales.

Sin negar la importancia de las fuerzas transnacionales y de la globalización económica para la formulación de políticas públicas, y a pesar de la importancia que la literatura le da a las modalidades transnacionales de ciudadanía, otros autores sostienen que el nivel real de inclusión social de las personas migrantes depende en gran medida del contexto específico del país, y para ser más preciso, de la combinación de la migración nacional y las políticas sociales (Banting; Guiraudon y Lahav; Hollifield; Sainsbury). Ni el Estado ni la ciudadanía han perdido la centralidad en relación con la extensión de derechos (Joppke). Por ejemplo, Guiraudon y Lahav argumentan que los Estados garantizan la soberanía del control migratorio al menos de tres formas, cambiando el nivel en el cual la política es elaborada e implementada: shifting up, shifting down y shifting out (Guiraudon y Lahav). Específicamente, para contrarrestar o evadir las restricciones normativas transnacionales, los Estados optan por un control migratorio más coordinado a nivel internacional (shifting up), descentralización de la política de inmigración a niveles locales (shifting down) y externalización de las funciones de control de la migración en el sector privado, que disciplina el comportamiento que no esté de acuerdo con las políticas de inmigración (shifting out).

Este artículo también desafía las perspectivas globalistas, al subrayar la importancia de los mecanismos legales y extralegales de exclusión que pueden ir de la mano con el reconocimiento oficial de los derechos humanos. Consecuentemente, y de particular importancia para este trabajo, la división entre legalidad versus "ilegalidad" se convierte en un mecanismo crítico para la exclusión. De este modo, esta investigación cuestiona contribuciones más recientes que minimizan la importancia de la "ilegalidad", y que tienden a confundir las políticas y los discursos políticos sobre la criminalidad de las personas inmigrantes y la "ilegalidad" (Agustín; Kalir; Kyle y Siracusa). Aunque estos enfoques se preocupan por enfatizar la agencia de la población inmigrante y no de reducirlos a "criminales" o "víctimas", sí minimizan la importancia de las políticas estatales -tanto en el papel como en la práctica- que condicionan en gran medida la agencia de las personas migrantes, así como sus experiencias de vida. 
Si bien las personas migrantes pueden establecer estrategias para la inclusión, estas se encuentran condicionadas considerablemente por el Estado (De Genova; Gonzáles y Chávez; McIlwaine; Willen). Además, la aplicación cada vez mayor de políticas estatales que criminalizan a las personas migrantes implica que dicha población está cada vez más sujeta a detención y deportación, así como a restricciones en su acceso a la política social y la integración (Walters et al.).

El acceso real de las personas migrantes a la política social va en contra de este contexto sociopolítico. Es decir, incluso cuando las personas migrantes tienen derechos formales a la política social, otros factores formales e informales, como la falta de información, las barreras lingüísticas y la xenofobia, pueden limitar el acceso real a los servicios sociales (Thomas y Gideon). Más allá de las restricciones a los derechos formales a través de políticas que penalicen a la población migrante, también existe un déficit de implementación, entendido como "la discrepancia entre los derechos formales y su práctica" (Soysal 134). Este déficit es especialmente relevante en los países desarrollados, donde existen mercados de trabajos informales más grandes y una menor capacidad institucional para proveer servicios sociales a las poblaciones nacionales. Así, las estrategias propias de las personas migrantes para acceder a la política social deben ser entendidas en el contexto de políticas estatales que buscan restringir, gestionar y controlar los derechos formales y el acceso real de estos individuos. Dichas estrategias, a menudo, implican recurrir al mercado de servicios de salud y medicina, tal como se mostrará a continuación.

Para Costa Rica, la ley de migración contemporánea ha creado importantes barreras para la integración a pesar de que existe un discurso más inclusivo (Fouratt, 2014b; Fouratt, 2016; Voorend y Venegas, 2014). Al mismo tiempo, estudios han demostrado que la incorporación con frecuencia es solo parcial, situación que reproduce vulnerabilidades y dinámicas de exclusión (López). De hecho, en Costa Rica, un estado migratorio regular, la membresía en los sistemas de seguridad social y la elegibilidad no son garantía de acceso a los servicios para las personas inmigrantes (Dobles, Vargas y Amador; López). Más bien, la atención del servicio público en la práctica depende mucho de quién está sentado en ventanilla. Esto hace eco sobre el argumento de que las prácticas reales de discriminación social, más que en el nivel de los derechos formales, son el problema real de la integración social (Faist, 1994; Pribble; Sainsbury).

Los estudios locales sobre el nexo entre la migración y la política social en Costa Rica se han enfocado, principalmente, en el marco institucional y legal que regula la migración (Fouratt, 2014b; Kron; Sandoval, 2012). Solamente López se enfoca explícitamente en el acceso a la atención médica, al argumentar que las personas inmigrantes legales solo se incorporan parcialmente, aspecto que reproduce vulnerabilidades y dinámicas de exclusión. Otros estudios, principalmente antropológicos, discuten las razones y efectos de tales exclusiones, concentrándose en las diferencias culturales y de género (Goldade; Spesny Dos Santos). 
Otros debaten la incidencia de las personas migrantes nicaragüenses o su impacto económico en los servicios sociales en Costa Rica; estas investigaciones parecen indicar que las personas migrantes generalmente no están sobrerrepresentadas como usuarias de los servicios de salud y si hacen un mayor uso de tales servicios, simultáneamente contribuyen más a ellos (Bonilla; Castillo). Los intentos de cuantificar el acceso real a los servicios están plagados de información incompleta sobre migrantes temporales o irregulares, ya que los datos oficiales de encuestas nacionales pasan por alto a la mayoría de estas poblaciones. Además, la mayoría de los datos oficiales de las instituciones nacionales de bienestar social no permiten la desagregación por nacionalidad, en el mejor de los casos agrupan a todas las personas migrantes juntas como extranjeras. Esta ambigüedad con respecto a la incorporación de la población inmigrante en los servicios sociales es lo que constituye el combustible para el fuego del discurso antiinmigrante en Costa Rica.

De este modo, el análisis de los mecanismos de exclusión aporta tanto a esta discusión sobre política social local como a una mejor comprensión de los procesos generales de exclusión social. Tales mecanismos pueden ser impulsados por el Estado, a través de criterios de elegibilidad más inclusivos o excluyentes, basados en el mercado mediante la inserción de migrantes en mercados laborales secundarios, inferiores e informales, o el resultado de la interacción entre los mecanismos estatales y de mercado -por ejemplo, el número de contribuciones necesarias para acceder a los beneficios de pensión-. Por último, los mecanismos de exclusión también pueden ser menos formales, y estar relacionados con prácticas diarias de discriminación y xenofobia, tanto en las instituciones públicas a cargo de política social como en el mercado laboral.

Tales mecanismos de exclusión pueden ser no menos importantes para las familias de las personas migrantes en el país de origen. En realidad, las remesas enviadas por las personas migrantes sirven como una estrategia para superar la exclusión social en el país de origen. El fervor inicial del llamado mantra de las remesas, la idea atractiva de que las remesas pueden canalizarse hacia inversiones económicas que conducen al desarrollo, ha dado paso a evaluaciones más matizadas de los impactos potenciales de las remesas (Kapur; Castles, Haas y Miller). Sin embargo, las remesas aún representan parches "sobre las deficiencias en los fondos públicos y en el financiamiento bancario que han aumentado gracias a la política neoliberal" (Grabel 6). En efecto, hay todavía un gran interés en los efectos multiplicadores respecto a las remesas colectivas, es decir, las asociaciones de migrantes reúnen recursos de los miembros para "respaldar la inversión pública proporcionando capital para clínicas de salud, tierras, pozos, irrigación, equipos y escuelas" (Grabel 17). No obstante, cuando las personas migrantes o las asociaciones de migrantes invierten en proyectos en su país tales como escuelas, clínicas, u hospitales, "participan en la privatización de los servicios públicos” (Hernández y Coutin 198). En Nicaragua, donde la cobertura y la 
calidad de los servicios públicos son insuficientes, las remesas significan un mecanismo clave para que la población migrante y sus familias compensen la falta de acceso a los servicios sociales públicos, ya sea porque estos últimos, simplemente, no existan, no se provea un servicio de calidad suficiente, como el caso en Nicaragua, o porque el acceso a los servicios sociales públicos sólidos es extremadamente difícil y la opción del mercado es más fácil.

\section{Migración y política social en Costa Rica y Nicaragua}

\section{Migración Nicaragua-Costa Rica}

Costa Rica alberga la mayor proporción de migrantes como porcentaje de la población total de casi todos los países de América Latina (Naciones Unidas, 2015). Los datos del censo de 2011 (INEC, 2011) muestran que las personas migrantes representan el $9 \%$ del total de la población, porcentaje significativamente mayor que otros países de destino importantes en la región, como Argentina (4.5\%) o Chile (3\%) (INDEC, 2010; INE, 2012). Primero, en respuesta a la inestabilidad y el conflicto regional desde la década de 1980 y, más tarde, debido a las políticas de ajuste estructural en la región después de la crisis de la deuda, Costa Rica recibió a un gran número de migrantes económicos y refugiados de América Latina. Entre 1984 y 2000, la población de inmigrantes en Costa Rica aumentó a una tasa promedio anual de $7.5 \%$, la mayor parte explicada por la afluencia de nicaragüenses (INEC, 1984; INEC, 2001). Entre el 2000 y el 2011, la población migrante creció anualmente en $2.4 \%$ en promedio (INEC, 2011). Junto con Estados Unidos, Costa Rica representó el principal destino para los 40000 nicaragüenses que migraron anualmente entre 2005 y 2010 (Baumeister, Fernández y Acuña).

En Costa Rica, los nicaragüenses, actualmente, representan el $75 \%$ de la población de migrantes, es decir, $6.7 \%$ de la población total (INEC, 2011). Estos flujos migratorios están directamente relacionados con la evolución de los sectores económicos clave de Costa Rica. Por ello, la población migrante que viene a trabajar es, generalmente, joven y poco calificada (Morales y Castro; Sandoval, 2007). En ciertos sectores, como la construcción, la agricultura y el servicio doméstico, los trabajadores migrantes nicaragüenses representan gran parte de la población total ocupada (Voorend y Robles, 2011). La reciente migración nicaragüense alcanzó su punto máximo en la década de 1990, debido al ajuste estructural y a los subsiguientes cambios en los mercados laborales (Sandoval, 2007).

A la luz de las recientes crisis financieras y de seguridad social, la migración nicaragüense se ha vuelto extremadamente polémica, en parte alimentada por una cobertura mediática negativa (Sandoval, 2012; González y Horbaty). La migración nicaragüense en la década de 1990 también coincidió con el declive del Estado benefactor 
costarricense. Al final de la década de 1990, comenzaron a surgir los impactos de los programas de ajuste estructural y la disminución de la inversión pública (IDESPO, UNFPA y Foro Permanente sobre Población Migrante, 2000; Nowalski y Barahona). Durante este periodo, la implementación de las políticas de ajuste estructural (PAE) en Costa Rica alentó la migración nicaragüense a través de la promoción de un sector exportador que demandaba mano de obra en gran escala y, al mismo tiempo, se redujo la capacidad del Estado costarricense para atender las necesidades de las personas dentro de su frontera.

No obstante, "el socavamiento de los servicios públicos y el recorte de la inversión pública usualmente están representados, no como una consecuencia de las políticas neoliberales, sino como un resultado de la migración nicaragüense a Costa Rica" (Sandoval, 2004, 444). Actualmente, la migración nicaragüense es imaginada popularmente como un problema social clave arraigado en las personas migrantes nicaragüenses que desplazan a los nacionales en el mercado laboral, a quienes se les considera, culturalmente, muy distintos y responsables de tasas de criminalidad más altas. Tres cuartas partes de la población costarricense creen que la población migrante nicaragüense tiene la culpa del debilitamiento de los servicios sociales públicos, en particular de la institución de salud y seguridad social emblemática del país, la CCSS (Dobles, Vargas y Amador).

Desde la década de 1990, Nicaragua ha experimentado una contracción dramática de los servicios sociales, los salarios y el empleo. Inicialmente, en la década de 1980, mientras la mayor parte de la región experimentó una reducción de los servicios sociales bajo un ajuste estructural, Nicaragua en realidad sufrió una expansión de programas y servicios bajo la Revolución Sandinista. Por primera vez, un gran número de nicaragüenses vio un acceso cada vez mayor a los servicios públicos, tales como la educación y la atención médica. Sin embargo, a medida que avanzó la década, los esfuerzos sandinistas de desarrollo social y económico se paralizaron, debido al embargo comercial de Estados Unidos y de la guerra en curso de la Contra. Durante el comienzo de la década de 1990, luego del fin de la Revolución, Nicaragua implementó los PAE, reduciendo los gastos gubernamentales en servicios sociales, salarios y empleo como una manera de ganar estabilidad económica (Babb; Mojica). Como resultado, el sector informal de Nicaragua creció para emplear, aproximadamente, a la mitad de la población económicamente activa (Nowalski). La migración llegó a ser una estrategia clave para garantizar la supervivencia familiar en Nicaragua. Hoy, alrededor del $10 \%$ de la población de Nicaragua continúa viviendo fuera de sus fronteras (Baumeister). Hasta el $40 \%$ de los hogares nicaragüenses reciben remesas de familiares en Estados Unidos, Costa Rica y Europa, y las remesas representan la mayor fuente de ingresos nacionales (Monge, Céspedes y Vargas, 2011). La mayoría de las remesas contribuye al consumo familiar básico, lo cual les permite a las familias cubrir sus necesidades básicas. 


\section{Política social y migratoria en Costa Rica}

En trabajos previos, se ha argumentado separadamente que la reciente política migratoria costarricense ha creado barreras a la integración de inmigrantes por medio de una ley restrictiva de migración y la interacción con la política social (Fouratt, 2014b; Voorend, 2013). Al hacer múltiples referencias a los derechos humanos internacionales, la Ley N. ${ }^{\circ} 8764$ (en vigencia desde 2010) compromete al Estado, por primera vez, a la inclusión social de las personas inmigrantes en la sociedad costarricense "basada en los principios de respeto a los derechos humanos; diversidad cultural; solidaridad; y equidad de género" (Ley N. 8764 , art. 3). En ese sentido, en el papel se comprende un enfoque más integral de la gestión de la migración, el cual incluye varios ministerios (Vivienda, Seguridad Social, Salud y Trabajo), así como organizaciones migratorias en informes y planificación. En realidad, la Ley orienta la inmigración no solo como una cuestión de seguridad, sino también como un problema de desarrollo.

Sin embargo, el reconocimiento de "la integración en procesos económicos, científicos, sociales, laborales, educativos, culturales, y deportivos" (Ley N. ${ }^{\circ} 8764$, art. 7) carece de un plan para operacionalizar la política pública (Noy y Voorend, 2016). Además, esta retórica de integración obscureció la securitización de la política migratoria (Fouratt, 2014; Kron, 2011). La Ley otorga más autonomía a la policía migratoria, instituye nuevas tarifas y multas y cambia los requisitos para obtener los permisos de residencia; además, añade, por ejemplo, el requisito de que los extranjeros casados con costarricenses deben esperar dos años de matrimonio antes de solicitar la residencia.

Igualmente importante es que la CCSS ahora juega un papel clave en el control de la migración interna (Voorend, 2013). La ley estipula que la afiliación al sistema de seguridad social de Costa Rica ahora se requiere para empezar un proceso de regularización (Fouratt, 2014b; Voorend, 2013). Esto no solo es muy costoso y burocrático para muchas personas migrantes, sino que en la práctica también elimina la posibilidad de un seguro indirecto para esta población sin un estatus migratorio regular. En combinación con una aplicación de la ley más estricta por parte de la CCSS, se ha vuelto extremadamente difícil para un paciente sin seguro recibir servicios de atención médica (que no sean de emergencia). Además, a raíz de una solicitud de la Dirección de Migración, la CCSS ahora solicita un estatus migratorio regular para el seguro, lo que deja a muchas personas inmigrantes irregulares en una situación de Catch-22: necesitan el estatus para obtener un seguro, pero deben estar asegurados para conseguir el estatus (Fouratt, 2014a y 2014b; Voorend, 2013). En general, la interacción de las políticas migratorias y las sociales ha creado barreras formales para el acceso de la población de inmigrantes a los servicios sociales y a la integración social en general. 


\section{Política Social, pobreza y exclusión en Nicaragua}

En Nicaragua, el Estado juega solo un papel marginal en la provisión de servicios sociales públicos. En este país, el aprovisionamiento social depende de la cooperación internacional y, especialmente, de las estrategias familiares (Martínez y Voorend, 2011). Aquí, las barreras de acceso no están relacionadas con el estatus de ciudadanía, sino con la mala cobertura y calidad de los servicios públicos. Si bien el gasto público social per cápita incrementó considerablemente entre 2000 y 2009, de USD 91 a USD 157; este gasto total es aún menos de la mitad del gasto total en atención médica en Costa Rica en 2009 (USD 343) (CEPAL). Y aunque la mayoría de los programas sociales en Nicaragua son universales por escrito, en la práctica solo están dirigidos a los pobres (Martínez Franzoni y Voorend, 2011 y 2012b). Por ejemplo, entre 1998 y 2005 la cobertura prescolar (entre 4 y 6 años) permaneció estancada en el $17 \%$ de la población elegible. Del mismo modo, en 2015, solo 38 \% de la población había asistido al menos a alguna escuela secundaria y el país solo tiene 3.7 médicos por cada 10000 personas (en comparación con los 11.1 de Costa Rica) (PNUD).

En consecuencia, las remesas, que representaron $9.8 \%$ del PIB en los primeros dos trimestres de 2015, desempeñan un papel importante para facilitar el acceso a los servicios sociales (BCN). Si bien los datos son escasos, las remesas son clave en el aprovisionamiento social de las familias nicaragüenses y casi la mitad de todas las remesas a Nicaragua se gastan en medicina, vivienda y educación (Martínez y Voorend, 2011).

\section{Esquivando al Estado en ambos lados de la frontera}

Aunque los servicios sociales universales y de alta calidad costarricenses contrastan drásticamente con los servicios insuficientes y de baja calidad de Nicaragua, en los dos países las familias nicaragüenses migrantes esquivan al Estado para acudir a servicios médicos privados. Sin embargo, las razones por las cuales se esquiva al Estado varían, según el contexto. En esta sección, se analiza el acceso que tienen las personas nicaragüenses a los servicios de salud, en ambos lados de la frontera, de acuerdo con los testimonios de las personas migrantes y sus familias.

\section{Costa Rica}

\section{El estado migratorio y la salud}

El acceso que tienen las personas nicaragüenses a los servicios sociales en Costa Rica varía de acuerdo con muchos factores, entre estos, el estado migratorio legal, el seguro social, la presencia de hijos y los procesos extralegales de discriminación. El estado migratorio es fundamental, no solo para el acceso a los servicios sociales, sino también para la integración en cualquier proceso. Tal y como apunta una mujer nicaragüense: 
Aquí sinceramente... sin cédula, uno no hace nada... sin seguro, aquí no somos nada, sin cédula no somos nada. Sin cédula no le dan trabajo, sin cédula no le dan una cita [médica]. Para todo se ocupa cédula... en todo el país (Diana, grupo focal, Pavas, 3 de mayo de 2014).

La aplicación más estricta de la ley, por parte de la CCSS, ha tenido efectos que las personas participantes sintieron. Ana explicó que su nieto (nacido en Costa Rica) no recibió atención médica aun cuando presentó un caso claro de urgencia.

Él estuvo gravecito, como se llama, cuando le da calentura se fue para hacer consulta y no lo atendieron solo porque no tenía seguro. No lo atendieron. Estaba gravísimo, no podía ni caminar de la calentura que se andaba (Ana, grupo focal, San Ramón, 30 de octubre de 2014).

Ahora con mi hijo tuve que ir a la farmacia a... comprarle para mientras. Pero, como le digo, si no está eso al día [seguro] aquí estamos listos... se nos cierra todo (Patricia, grupo focal, Pavas, 20 de agosto de 2014).

Aunque muchas personas migrantes reúnen condiciones que los hacen elegibles para un estado legal, por ejemplo, lazos familiares de primer grado (como padre o madre de un niño o niña costarricense), el proceso de regularización no es fácil y el estado migratorio legal no parece ser condición suficiente para el acceso a los servicios sociales. Según las personas de los grupos focales entrevistadas, casi todos con empleo informal mal remunerado, los altos costos del proceso de regularización representan un gran obstáculo. Un inmigrante calculó que el costo de estos trámites supera los USD 1200 (Pedro, grupo focal, Alajuelita, 26 de enero de 2014).

A uno se le hace difícil sacar esos papeles, porque vea, si yo meto los papeles... no paga la casa, me echan. Y si meto los papeles, no puede pagar ni el uno ni el otro. Se le hace duro el costo a uno (Isabel, grupo focal, Pavas, 3 de mayo de 2014).

La plata es lo que hace difícil para hacer sus papeles (Dora, grupo focal, Pavas, 20 de agosto de 2014).

Sofía, madre de tres hijos, mencionó lo cansado y costoso que fue para ella el proceso para conseguir sus documentos legales.

Yo fui hace dos años [a Nicaragua]... y yo pagué el trámite rapidito. ¿Cuánto, cien córdobas? ¿Cuánto, cien dólares? [Ellos] se aprovechan de la necesidad de uno... y yo aquí por lo menos dos o tres días. Esa es la esperanza de uno y no una semana. Pagando el trámite, y bueno, si no tiene certificado de nacimiento... no le doy el récord de policía, entonces un día para el certificado de nacimiento. ¡Cien córdobas! Otro día para el récord de policía, veinte dólares. 
Otro día para no sé qué cosa, veinticinco dólares. Viene uno aquí al banco y cincuenta y ocho mil colones, más veinticinco dólares de no sé qué, más treinta dólares de no sé cuánto. Había que pagar estadia, igual otra vez aqui, a pagar la autenticada de cada documento. A pagar, y bueno enseñar... que uno tenía boleto de entrada y de salida del país. Y todo eso igual, los documentos, para los hijos de uno (Sofía, grupo focal, Alajuelita, 26 de enero de 2014).

De hecho, es común encontrar personas nicaragüenses elegibles para una residencia legal, gracias a sus conexiones familiares con costarricenses; no obstante, estas permanecen indocumentadas, debido a los altos costos que implica el proceso de regularización. En especial, de acuerdo con la literatura, este análisis sugiere que, por las diferencias de género en el tipo de inserción laboral, las mujeres tienen más posibilidades de ser las últimas de la familia en obtener el estado migratorio legal. Lo anterior provoca que estas féminas enfrenten menores probabilidades de acceder a los servicios de salud (Goldade). Por ejemplo, Yolanda, una mujer indocumentada con cuatro hijos, indicó que su esposo era residente legal, al igual que su hija de 17 años de origen nicaragüense; mientras que sus otros dos hijos, de origen costarricense, eran ciudadanos. Sin embargo, ella seguía indocumentada:

Él obtuvo su residencia hace ya casi tres años, porque, bueno usted sabe, estaba trabajando. Lo hicimos así a propósito, para que ganara mejor. Él trabaja en construcción. En el servicio doméstico, uno no gana tan bien, y no te piden [la residencia]. En construcción sí (Yolanda, comunicación personal, 14 de febrero de 2012).

Otros participantes mencionaron las dificultades burocráticas en el proceso de regularización. El proceso conlleva obtener una gran cantidad de documentos del país de origen, además, realizar visitas a muchas instituciones públicas en Costa Rica, tales como las oficinas de migración y algunos bancos. La reforma migratoria del 2009 implicó que este proceso se convirtiera en un asunto mucho más complejo y costoso, tal y como se aprecia en los relatos de varias personas participantes:

Es mucho más difícil ahora que antes. Ahora piden mucha cosa (Isabel, grupo focal, Pavas, 3 de mayo de 2014).

Piden un montón de papeles... Tienen que ir a Nicaragua a traer récord de policía, partida de nacimiento autenticada, la constancia [de nacimiento] que tiene que ir timbrada a no sé cuánto vale. Tiene que ir a pedir una carta al consulado. De ahi, es ir a meter todito a [migración], a ver si le da la gana a migración si la aprueba o no. Y [si] no te la aprueban, entonces toda esa plata queda perdida ahí, con el costo y el sacrificio que uno hace (Carolina, grupo focal, Pavas, 3 de mayo de 2014). 
Y vea que tremendo es, porque si usted no está asegurado y va a renovar cédula... no la puede renovar. Mientras no tienen la orden patronal, y si no está trabajando, ¿cómo le hace uno? (Juliana, grupo focal, Pavas, 3 de mayo de 2014).

Antes de 2010 (cuando entró en vigor la Ley de Migración de 2009) las personas inmigrantes podían adquirir el seguro de una forma más sencilla, ya que no estaba condicionado a un estado migratorio legal. Tanto residentes regulares como inmigrantes irregulares podían acceder a los servicios de salud, si comprobaban que estaban asegurados por sus patronos, o bien, que pagaban la cotización del seguro voluntario. Además, dada la aplicación menos rigurosa de las normativas de la CCSS, antes de 2011, los criterios formales de elegibilidad tal vez no eran el principal condicionante para que las personas inmigrantes accedieran a la salud pública; antes bien, sí lo eran los costos que implicaba obtener y mantener un seguro social. Sin embargo, con la situación del Catch-22, creado entre el año 2009 y el 2011, el acceso a servicios de salud resultó más difícil para inmigrantes en condición irregular.

Asimismo, los requisitos administrativos implican un suplicio burocrático para las personas migrantes que tratan de navegar el sistema. Desde que se implementó la Ley, ha surgido una falta de comunicación y de coordinación entre instituciones estatales encargadas de los procesos de residencia y de la solicitud del seguro médico (Fouratt, 2014a, 2014b). Por ejemplo, en el 2012, un abogado migratorio de una ONG nacional informó que existían dificultades y conflictos para las personas nicaragüenses al momento de pagar las cuotas de solicitud:

No es tan sencillo como ir a un banco y pagar una cuota, porque no tienen seguro... Así que llegan al banco y... no pueden pagar porque no tienen seguro. Y cuando van a la oficina del seguro, les dicen que no pueden afiliarse porque su residencia está vencida (Anónimo, comunicación personal, 2012).

Debido a que cada etapa del proceso involucra que las personas migrantes cumplan con otros requerimientos, la falta de coordinación entre los bancos, la Caja y las oficinas de inmigración han generado conflictos casi imposibles de resolver.

\section{Acceso a la salud: Seguro y discriminación}

La falta de claridad provoca que los empleados de ventanilla y otros trabajadores del sector público, que laboran en el ámbito administrativo, utilicen mayores grados de libertad para determinar sus propios criterios en relación con el proceso de regularización u obtención del seguro. Así pues, existen muchas anécdotas sobre ciertas formas explícitas y no tan explícitas de discriminación y exclusión, incluso de inmigrantes que cuentan con documentación legal. 
Diay, siempre, siempre se encuentra uno en migración, personas que, como le digo, son ángeles y hay otras que, como dicen, amanecen con el chingo al revés. Si, se levantaron con la pata izquierda... porque desde que llegan es una amargura. ¡Una amargura! Porque yo, cuando llegaba a meter los papeles, siempre era "vea este, mamita, este papel no entró. Tráigalo, vaya búsquelo y vuelve". Al otro día, no está, porque la cambiaron, y: "Vaya, busque un papel", porque no se fijó al leer. [Y cuando lo entrego y digo] "Aquí está el que la muchacha [de ventanilla] me dijo ayer" [Ellos responden] "Nooooo, no es ese, es otro. ¡Vaya búsquelo! (Carmen, grupo focal, Alajuelita, 26 de enero de 2015).

Aunque la mayoría de las personas participantes afirmaron que, por lo general, reciben atención médica cuando tienen seguro médico, algunas personas inmigrantes enfrentaron prácticas de exclusión, a pesar de ser legalmente elegibles para el acceso a estos servicios; un asunto que evidenciaron algunos estudios previos (Goldade; López).

Sí, mi hijo mayor me asegura... él trabaja. Sí, yo presento la orden [patronal], pero no me atienden. Me dicen que no, que tengo que tener mis documentos al día (Isabel, grupo focal, Pavas, 3 de mayo de 2014).

Estuve con colilla [orden patronal] durante seis meses... Con una empresa, llevé mis documentos y me dicen que me rechazaron, porque soy turista (Fabián, grupo focal, Carrillo, 18 de octubre de 2014).

No obstante, incluso aquellas personas que logran el acceso formal, por medio de la afiliación a la CCSS, pueden enfrentar obstáculos cuando requieren los servicios de atención médica. Cuando se les preguntó a las personas participantes sobre la existencia de prácticas discriminatorias, la mayoría de las anécdotas corresponden al sector educativo, en particular, se trata de acoso escolar hacia los hijos de nicaragüenses: "se discrimina a muchos niños por ser inmigrante" (Karla, grupo focal, San Ramón, 30 de octubre de 2014).

Se consultó, específicamente, sobre la discriminación en el sector salud; al respecto, surgió un abanico de distintas respuestas. Una participante afirmó que "a veces creo que el seguro atiende mejor a los nicaragüenses que a los propios ticos" (Graciela, grupo focal, San Ramón, 30 de octubre de 2014); sin embargo, algunas personas inmigrantes indicaron que se han sentido ofendidas o discriminadas en las clínicas públicas.

Si, a veces, en realidad, nos maltratan mucho. Pero ellos se aprovechan de la necesidad de la gente y los maltratan... Claro, que si pueden hasta le pegan a uno. ¡Dios libre, uno le pegue! Tras de que es "nica" viene a jugar de vivo, y tome... Si le tiran los documentos hay que quedarse callado, decir "muchas gracias". Es que, diay, ¿qué va a hacer uno? (Luz, grupo focal, Alajuelita, 26 de enero de 2014). 
Para algunas personas inmigrantes, cualquier interacción con la burocracia costarricense implica enfrentarse con la xenofobia y a la discriminación.

En la mayoría de los casos, se topa uno [con discriminación]. En todo, ya sea en un banco: la cédula nicaragüense y ya la empiezan a tratar mal a uno. Donde quiera que usted vaya y le toque enseñar la cédula... uno se topa con personas que ya le empiezan... a hacer caras (Sarah, grupo focal, Alajuelita, 26 de enero de 2014).

Así como en el caso del estado migratorio legal, la integración al seguro médico público parece estar condicionada por relaciones de género. Comúnmente, por la organización familiar, las mujeres nicaragüenses obtienen el seguro después de que sus cónyuges e hijos lo logran adquirir, en caso de que lo puedan tramitar. Karina, una joven madre de dos niños pequeños, mencionó:

Aquí solo tienen [seguro] los dos chiquitos y mi esposo, menos yo. Yo puedo estar enferma y si me muero, [pero] no tengo plata para pagar una cita médica privada (Karina, grupo focal, Pavas, 20 de agosto de 2014).

Los grupos focales sugieren que las personas inmigrantes nicaragüenses adultas enfrentan obstáculos para acceder a los servicios de salud y que estos obstáculos no solo se vinculan con condiciones laborales y de vida precarias o con las políticas migratorias restrictivas cada vez más rigurosas (Castañeda), sino que también se deben a la estigmatización y discriminación. Carlos, quien vive en Guanacaste, lejos del Valle Central, señaló:

Que esa xenofobia [está presente] más en San José, por linaje... etnia... la raza. Que nosotros somos morenos, es un poco más notorio. En San José nosotros somos más notorios (Carlos, grupo focal, Carrillo, 18 de octubre, 2014).

\section{Acceso para los niños}

Las personas participantes indicaron que, por lo general, sus hijos e hijas tienen acceso a los servicios públicos. En realidad, para las personas menores de edad es bastante fácil acceder a estos servicios. Primero, el marco legal de Costa Rica les garantiza a los menores de edad el acceso universal a la atención médica y a la educación, independientemente del estado inmigratorio. Segundo, muchas personas migrantes nicaragüenses tienen hijos con ciudadanía costarricense, gracias al principio de ius soli. Spesny Dos Santos (2015) argumenta que estos infantes no se consideran "auténticos costarricenses" y se catalogan en torno a una "ambigüedad simbólica... y probablemente siempre vayan a ser considerados como inmigrantes de primera generación" (5). Aunque lo anterior puede ser cierto, la cédula costarricense sí les da una ventaja sobre aquellos infantes de 
origen nicaragüense, al menos en términos legales. Sobre todo, las madres destacaron la relativa disponibilidad de servicios y el fácil acceso a estos que gozan sus hijos e hijas.

Bueno yo estuve en emergencia con ella [la hija] y en el Hospital de Niños, en ese momento sí me la atendieron bien... Pero, me la atendieron con esa condición, de que, si ella volvía a recaer, yo tenía que tener los documentos de ella en regla, y principalmente los míos. Si, pero la primera vez a ella me la atendieron excelente (María, grupo focal, San Sebastián, 7 de agosto de 2014).

La población que está protegida son los niños. Sí, es cierto, aqui hay un hospital de niños que lo atiende, esté asegurado o no esté asegurado (Adriana, grupo focal, San Sebastián, 7 de agosto de 2014).

Si bien se trata de excepciones, surgen experiencias que demuestran la existencia de ciertas complicaciones para que los menores de edad puedan acceder a los servicios de salud. Por ejemplo, la hija de Sofía, Karla, tenía 6 meses cuando su madre emigró al país, pero no traía su certificado de nacimiento. Según comentó Sofía, a causa de un problema complejo con el padre de Karla, nunca pudieron volver a Nicaragua a recuperar el certificado, requisito fundamental para el proceso de regularización. Hace poco tiempo, Karla, quien tiene actualmente 9 años, necesitaba atención médica, pero la CCSS se la negó:

Sí, le han negado el derecho a mi hija, en el Hospital de Niños. A la que no tiene residencia ni nada, a la que está ilegal, sí me le han negado el derecho. Claro, pero como yo sé que tenemos derechos también, apenas yo les menciono que voy a denunciarlos, de una vez me mandan a validación de documentos. Pero claro, ya la vieron de mala gana. Y jtome! No hay medicina (Sofía, grupo focal, Alajuelita, 26 de enero de 2014).

Ahora bien, el hecho de que los niños gocen de acceso a la salud no significa necesariamente que sirvan como "catalizador" para que sus familiares adultos también lo adquieran. Muchas veces, las personas inmigrantes adultas creen que ellas no merecen los servicios médicos y, por ende, no los solicitan, a menos de que sea estrictamente necesario. Un participante lo explicó de la siguiente manera:

Es una cosa sentir que el hijo tiene derecho a la salud, pero es otra cosa completamente sentir que uno tiene ese derecho para uno (Pablo, grupo focal, Alajuelita, 26 de enero de 2015).

\section{Opciones privadas}

Frente a las dificultades de acceso a los servicios sociales públicos, muchas personas inmigrantes buscan otras opciones, en especial cuando se trata de servicios de 
salud. Dichas opciones varían entre las personas entrevistadas, pero casi siempre coinciden en sufragar servicios de salud privados. La alternativa más recurrente es pagar por servicios médicos en el sector privado, tanto por citas médicas como por medicinas.

No estoy asegurada, y cuando yo me siento... mal, lo que hago es ir a una farmacia si tengo la plata. Y si no, me aguanto (Dora, grupo focal, Pavas, 20 de agosto de 2014).

Mi mamá no tiene cédula. Entonces, para que la atiendan a ella... los hermanos tenemos que ver cómo hacemos y pagar clínica privada (Martha, grupo focal, Alajuelita, 26 de enero de 2015).

Como parte de estas opciones privadas, las personas inmigrantes idean estrategias para evitar los altos costos de los servicios de salud privados en Costa Rica. Por ejemplo, un inmigrante indica: "lo mandamos a traer de Nicaragua, o el mercado negro, que le dicen. Al parque a La Merced llega mucho nicaragüense y a escondidas" (Carlos, grupo focal, San Sebastián, 7 de agosto de 2014). En tales casos, las personas participantes dijeron "preferimos auto medicarse... y adivinando que será, que no será" (Stefani, grupo focal, San Sebastián, 7 de agosto de 2014).

Algunas opciones comunes incluyen prácticas clandestinas de importación de medicamentos desde Nicaragua. Por lo general, las medicinas que se traen de Nicaragua provienen de "farmacias privadas donde tiene que pagar la consulta con el médico [para el paciente en Costa Rica] y el medicamento que le manden" (Isabel, grupo focal, Pavas, 3 de mayo de 2014).

Nosotros lo que hacemos es que compramos... Nosotros mismo vamos allá [a Nicaragua] con las recetas, o tenemos que pagar caro. Aqui es caro en la farmacia. Hay gente que trae de Nicaragua grandes sacos... porque el nicaragüense está usando ese, la medicina que viene de allá e inclusive costarricenses que pagan seguro compran a esa gente... en el parque de La Merced... Así es la cosa, "Ando penicilina, ando esto, ando lo otro", entonces uno solo baja ahí (Fabián, grupo focal, Carrillo, 18 de octubre de 2014).

Cuando las personas inmigrantes carecen de seguro médico evitan a toda costa ir a la CCSS y cuando se sienten mal van "a la pul [pulpería], a comprarse una pastilla" (Xinia, grupo focal, Pavas, 20 de agosto de 2014). Algunas personas entrevistadas mencionaron que regresan a Nicaragua para recibir atención médica, ya sea en el sistema de salud público o en el centro de salud privado más económico que puedan encontrar: "Si no tenés seguro aquí, es mejor volver a tu país" (Isabel, grupo focal, Pavas, 3 de mayo de 2014). Tal y como Rafaela explicó con crudeza: 
Somos como elefantes, que, cuando nos sentimos mal volvemos a nuestro lugar de nacimiento... Si, un elefante puede viajar y viajar y viajar, iverdad? Pero cuando se siente que se va a morir, vuelve al lugar donde nació. Y ahí se muere. Si, así somos nosotras [mujeres migrantes]. Cuando nos enfermamos, y sentimos que es, bueno, terminal, porque no tenemos un seguro que nos atiende, y cuando nos vamos a la clinica, no nos atienden... Tenemos seis compañeras que se murieron de cáncer, porque no tenían acceso a salud, no lo tenían a tiempo. Y por eso, sí, la mayoría de nosotras decidimos volver a nuestro país. Para morir ahí (Rafaela, comunicación personal con Fouratt, Sabanilla, 14 de noviembre de 2011).

Sin embargo, ante casos de emergencia, las personas migrantes no tienen otra opción más que acudir a la atención médica de Costa Rica. En estas situaciones, tal y como ordena la CCSS, luego de que la persona recibe la asistencia médica se le brinda una factura por los costos del servicio que debe pagar. Entonces, casi todas las opciones de los servicios sociales públicos involucran el pago por parte de las personas migrantes.

\section{Nicaragua}

Si las personas inmigrantes en Costa Rica recurren a medios privados para acceder a los servicios médicos, sus familiares en Nicaragua adoptan estrategias similares. En Nicaragua, los obstáculos para acceder a la salud no se vinculan con el estado legal de los ciudadanos; estos están relacionados con la baja cobertura y la escasa calidad de los servicios públicos. Aunque la inversión social pública (total) per cápita aumentó substancialmente entre el año 2000 y 2009, de USD 91 a USD 157, esta inversión fue aún menor que la mitad del monto per cápita que Costa Rica invirtió solo en salud pública (USD 343) en el 2009 (CEPAL).

Muchos de los programas sociales en Nicaragua son, en teoría, universales; no obstante, en la práctica, se dirigen solo a los pobres y no logran una cobertura significativa (Martínez Franzoni y Voorend, 2012a, 2012b). Por ejemplo, entre los años 1995 y 2005, la cobertura escolar (de infantes entre los 4 y 6 años) permaneció estancada en un $17 \%$ de la población elegible. De igual forma, en el 2015, solo el $38 \%$ de los habitantes disfrutó de al menos un grado de educación secundaria y el país solo contaba con 3.7 médicos por cada 10000 habitantes (en comparación con los 11.1 médicos en Costa Rica) (PNUD). En efecto, las personas inmigrantes en Costa Rica destacan la calidad de los servicios sociales del país, en contraste directo con lo que percibieron en Nicaragua: una falta de servicios de calidad.

Sin embargo, a pesar de este contexto, nadie en los grupos focales mencionó el acceso a la salud pública de calidad como un factor importante por el cual se decidió emigrar a Costa Rica. Un participante claramente se molestó cuando se le preguntó si había tomado en cuenta los servicios sociales de Costa Rica cuando inmigró: 
Mira, uno cuando está en Nicaragua, uno no piensa eso. ¿Vos crees que uno va a analizar dónde va a ir, si quiere salir de ahí dónde está? ¿Cómo yo voy a... analizar a dónde voy a ir si no tengo ni para los pases? ¿Primero voy a pensar si la seguridad en Costa Rica está mejor o si el seguro social en Costa Rica es mejor que Nicaragua? Uno no piensa eso... uno piensa así: no tengo trabajo, no como, como una vez por día, a veces ni cómo. ¿Cómo es esa ocurrencia pensar en analizar dónde voy a ir, si lo que quiero es salir de ahí? (Ignacio, grupo focal, San Sebastián, 7 de agosto de 2014).

A pesar de este tipo de argumentos, en algunos casos el acceso a la salud sí impulsa la decisión de emigrar. Tales casos, sin embargo, siempre estuvieron relacionados con alguna condición médica que no podía ser tratada en Nicaragua. Por ejemplo, Fouratt (2014a) entrevistó a una familia inmigrante donde una de las hijas padecía de un problema cardíaco y necesitaba medicamentos muy costosos, los cuales el sistema de salud nicaragüense no podía cubrir. Como agricultores de escasos recursos que vivían en una zona rural de Nicaragua, les era difícil comprar las medicinas que la niña necesitaba mensualmente. Ante este panorama, lo único que podían hacer era migrar a Costa Rica para trabajar ahí y recibir salarios más altos. No obstante, en lugar de comprar los medicamentos en Costa Rica y enviarlos regularmente a su hija en Nicaragua (dadas las tarifas de importación y envío), ellos preferían enviar dinero a su hija mayor para que comprara el medicamento en Nicaragua. Este tipo de envío de dinero para la compra de medicinas es un método común entre familias migrantes nicaragüenses, principalmente porque, como varias personas participantes mencionaron, la variedad de los medicamentos gratuitos del sistema de salud público nicaragüense es muy limitada.

Además, el pagar por servicios médicos en clínicas y hospitales privadas puede dejar a personas nicaragüenses con deudas considerables. Como en otros países en América Latina, las deudas comúnmente impulsan la migración (Mahler; Miles; Stoll). Por ejemplo, Kenneth, un hombre joven de 20 años que vivía en Granada, relató la experiencia traumatizante que experimentó cuando llevó a su novia embarazada al hospital por una infección renal. En el hospital público, el personal médico les advirtió sobre la posibilidad de sufrir un aborto a causa de la infección, pero, al mismo tiempo, se negaron a realizar un ultrasonido para verificar el estado del feto:

Entonces ahi en el hospital hacen ultrasonidos, pero dijeron que una de las máquinas no funcionaba y que solo hacian ultrasonidos para los embarazos más avanzados, como de siete y ocho meses. Entonces, yo no sabía qué hacer. Yo fui a pedir plata prestada para un ultrasonido afuera [privado] (Kenneth, comunicación personal con Fouratt, Granada, 13 de junio de 2012).

En este caso, Kenneth le pidió un préstamo a su patrono y llevó a su novia a una clínica privada para realizarle el ultrasonido; posteriormente, la llevó nuevamente al hospital público para que le dieran el tratamiento contra la infección renal. 
Esta insuficiencia en la calidad y la falta de ciertos servicios se complica aún más por la expectativa común de que la persona que usa los servicios públicos de salud, educación o beneficios de vivienda, debe realizar alguna contribución voluntaria, ya sea de trabajo, dinero o de artículos.

Otras familias mencionaron que usan las remesas para pagar servicios de salud que van desde ultrasonidos y medicinas, hasta citas médicas en clínicas privadas. Con frecuencia, las familias migrantes utilizan las remesas para que sus hijos e hijas accedan a servicios de salud en el país de origen. Sin embargo, por lo general, estas remesas se designan para gastos recurrentes de salud, educación, alimentación y otras necesidades, así que, si es necesario usarlas en asistencia médica de emergencia, podrían verse seriamente afectados los ya ajustados presupuestos familiares. Marina, una abuela que cuida a sus dos nietos en Nicaragua, mientras su hija trabaja en Costa Rica, explicó que, cuando los menores se enferman, casi siempre los lleva a una clínica privada:

Cuando se enferman, yo los llevo... sobre todo porque no tienen seguro acá. Entonces, yo los llevo a un doctor. Si los llevás a una clinica, iverdad, a una pública? y no los atienden, entonces tenés que llevarlos a un doctor pagado... Yo los tengo que llevar a un doctor privado para que prestan más atención a la enfermedad. En todo esto tengo que pensar, y esto es mi responsabilidad (Marina, comunicación personal con Fouratt, Managua, 1 de septiembre de 2012).

Aunque existen pocos datos al respecto, esto parece reafirmar hallazgos anteriores. Martínez Franzoni y Voorend (2012a, 2012b; 2011) señalan que las remesas son fundamentales para la prestación de servicios sociales en las familias nicaragüenses. Ellos sostienen que casi la mitad de las remesas que entran a Nicaragua se usan para los gastos de medicamentos, vivienda y educación. Lastimosamente, estos datos no permiten mayor desagregación, pero sí demuestran que las remesas juegan un papel crucial en el financiamiento de las prestaciones sociales.

La dependencia de las remesas para el acceso a servicios médicos, en especial, la atención médica para los hijos crea con frecuencia conflictos entre las familias transnacionales, entre la persona que manda remesas y la persona encargada del cuido en Nicaragua. Por ejemplo, la misma Marina indicó que guardaba todos los comprobantes de pagos por servicios, exámenes y medicinas de sus nietos, con el fin de evitar malentendidos con la madre de los menores en Costa Rica.

En otros casos, cuando la persona que migró ya no puede enviar remesas, puede verse seriamente afectado el acceso de los infantes a servicios médicos. Por ejemplo, Esther, encargada de su nieta de 13 años, dijo que fue muy frustrante cuando el padre no envió dinero durante varios meses, mientras que la niña estaba padeciendo de dolores de cabeza periódicos: 
Yo no sé. Parece que le fue mal económicamente. Eso es lo que siento. Porque Jessy ha estado muy enferma, estuvo en el hospital, y casi no habia ayuda de él, casi ausente. La diferencia que hubiera hecho un escaneo [CT]. Pero eso cuesta casi USD 200. Y él no podía mandar eso. Entonces, no le hemos conseguido el escaneo (Esther, comunicación personal con Fouratt, Managua, 17 de julio de 2012).

Así, la falta de remesas puede impedir el acceso a los servicios de salud, en especial para hijos e hijas de migrantes, quienes dependen del envío de dinero para poder cubrir sus necesidades básicas. En un contexto de gran insatisfacción por los servicios de salud pública en Nicaragua, la migración y el envío de remesas representan una manera en la cual las familias pueden evadir los servicios brindados por el Estado y costear la atención médica en el sector de salud privado.

Debido a los altos costos de estos servicios y a la inestabilidad de las remesas, muchas familias tienen que combinar el pago de medicamentos, exámenes privados y citas con especialistas con los servicios de salud básicos del sector público. Entre las familias que dependen de estas prácticas de prestación privada de salud, se manifestó un descontento general con el Gobierno de Nicaragua, al cual consideran un explotador de la clase trabajadora para salvaguardar sus propios intereses.

Resulta interesante que, a pesar de los distintos contextos entre Costa Rica y Nicaragua, se pueden observar similitudes en los dos países, en cuanto a las formas en que las familias migrantes acceden a servicios médicos: el sector privado de salud sirve como un mecanismo clave para hacer frente a la exclusión del sector público de salud en Costa Rica y a la insuficiencia de los servicios brindados por el sector de salud pública en Nicaragua.

\section{Conclusiones}

El análisis proporcionado anteriormente sugiere que, como miembros de familias transnacionales, las personas nicaragüenses en Nicaragua y en Costa Rica adoptan prácticas mercantilizadas muy similares de estrategias de bienestar. Es decir, para las personas migrantes adultas en Costa Rica, o sus familias en Nicaragua, los servicios sociales públicos, a ambos lados de la frontera, juegan un rol limitado en la provisión de servicios de salud. En cambio, las personas nicaragüenses han desarrollado estrategias que esquivan al Estado para acceder a la atención médica y a otros servicios para los miembros de la familia. Las razones para esta evasión, sin embargo, son específicas del contexto.

En Costa Rica, los mecanismos de exclusión de los servicios sociales públicos toman la forma de un marco legal estricto y la interacción entre el estatus de migración regular y la afiliación a la seguridad social. El impasse legal aparentemente irresoluble en el que la regularización depende de la obtención de la seguridad social y viceversa, a pesar 
de haberse resuelto oficialmente en la Corte Suprema, crea una pesadilla burocrática para las personas migrantes por falta de claridad con respecto a los procedimientos y protocolos, mientras le da al proveedor de servicios o al empleado de ventanilla mucha libertad para decidir sobre los requerimientos para acceder a los servicios sociales.

No obstante, más importante son los altos costos relacionados con la regularización y la seguridad social. Las preocupaciones de las personas migrantes sobre estos altos costos fueron recurrentes en el trabajo de campo que abarca un periodo de seis años, y para la mayoría de ellos resultan un obstáculo insuperable para regularizar. Estos mecanismos de exclusión legales impulsados por el Estado demostraron la importancia del estado de la ciudadanía y del estado denizenship para la integración, a pesar del mayor reconocimiento discursivo de los derechos humanos, en marcado contraste con los argumentos globalistas que sostienen la desaparición de la soberanía estatal frente a marcos normativos internacionales que los obligarían a otorgar amplios derechos sociales a los recién llegados.

De hecho, cuando la integración se reduce a la legalización, pero la discriminación y la xenofobia están arraigadas socialmente, plantea un espectro problemático de migrantes quienes pueden tener el derecho al estatus legal, pero que, prácticamente, no pueden acceder a sus derechos sociales. Por lo tanto, el análisis subraya la importancia de ir más allá del reconocimiento formal de los derechos y extender el análisis de los derechos (sociales) al acceso real a los servicios. La forma en que el acceso institucional se enmarca en la ley tiene impactos reales en la vida de las personas migrantes, como atestiguan las cuentas de las personas migrantes. Además, este marco está tan arraigado socialmente que aquellos que implementan las políticas, e incluso aquellos que necesitan servicios, no pueden alejarse de esta división legal/ilegal.

Las mismas personas migrantes apuntan a experiencias xenofóbicas negativas cuando adquieren servicios de salud, a la negación rotunda del acceso por completo, o a las personas migrantes que no se acercan a las instituciones de servicios sociales porque sienten que no merecen sus servicios. Estas cuentas de migrantes subrayan que el estado legal y la afiliación a la seguridad social son condiciones necesarias, pero no son suficientes para acceder a los servicios sociales. Finalmente, debido a la importancia de las estrategias de salud mercantilizadas, el acceso a los servicios de salud está directamente mediado por la integración de las personas migrantes en los mercados laborales y la obtención de los fondos necesarios para pagar dichos servicios que, a su vez, está mediado por la "legalidad".

De manera similar, este análisis cuestiona el argumento del imán de bienestar, la percepción constante entre la población costarricense de que las personas nicaragüenses emigran al país y están sobrerrepresentados en los servicios sociales "excepcionales". Es verdad que en Nicaragua el Estado juega un papel menor en la provisión social y que la falta de servicios sociales públicos pesa en la decisión de migrar. No obstante, no es sencillo suponer que las personas nicaragüenses establecen una relación 
con los servicios públicos en su nueva sociedad de acogida. Si bien el acceso es más común entre los niños y las personas migrantes pueden regularizar su estatus migratorio por medio de sus hijos nacidos en Costa Rica, no necesariamente acceden a los servicios sociales para sí mismos.

El hallazgo de estrategias mercantilizadas para acceder a los servicios de salud no solo contribuye a la comprensión de las reacciones a los procesos de exclusión social, sino que también contribuye al entendimiento de políticas sociales universales en contextos de desarrollo. La opción de mercado no es solo una alternativa al universalismo para los sectores de la clase alta de la sociedad cuando la calidad general de los servicios se erosiona; también es clave para los sectores más pobres de la sociedad cuando son excluidos de los servicios universales por mecanismos legales y extralegales (Dobles, Vargas y Amador; Martínez y Sánchez). En Costa Rica, las dificultades financieras y de gestión de la Caja empuja incluso a la población costarricense con la cobertura del seguro para buscar pruebas de diagnóstico y procedimientos de rutina en el sector privado. En Nicaragua, la baja calidad de los servicios lleva incluso a la clase trabajadora pobre al sector privado, lo que impulsa la deuda y contribuye a la migración.

Como muestra este análisis, la agencia de las personas migrantes en sus propias estrategias de bienestar está directamente mediada no solo por la "legalidad", sino también por el poder adquisitivo. Curiosamente, las remesas de Costa Rica a Nicaragua no solo facilitan las prácticas mercantilizadas de acceso a la atención médica en Nicaragua, sino que también, debido a los altos costos de la medicina privada en Costa Rica, no es raro obtener medicamentos en el mercado negro o importarlos de Nicaragua. De manera similar, dependiendo de la gravedad del caso, si el acceso a los servicios públicos de salud es imposible en Costa Rica, las personas migrantes regresan a Nicaragua para buscar atención médica ahí, a menudo en el sector privado relativamente más barato. En este sentido, las personas migrantes participan en procesos transnacionales de provisión social que, si bien están condicionados por las políticas estatales, trascienden las fronteras nacionales.

La importancia de la mercantilización del acceso a los servicios sociales es un hallazgo clave, directamente relacionado con el tipo de relación que las personas migrantes establecen con el Estado. En última instancia, crea desincentivos tanto para el Estado costarricense como para el Estado nicaragüense para garantizar la protección social de estas poblaciones. En Nicaragua, esto sucede debido a la poca capacidad institucional y a una cultura de no exigir servicios del Estado, ya que nunca estuvieron presentes, así como la gran afluencia de remesas, las cuales hacen que la compra de medicamentos y atención médica sea posible para muchas familias.

En Costa Rica, el Estado ha creado convenientemente una situación restrictiva, a través de políticas migratorias y aplicación de la ley, en la cual reconoce discursivamente la importancia de la "integración" y los "derechos humanos", pero en la práctica limita el acceso a los servicios sociales para personas externas. Tales límites están 
legitimados por la cobertura de medios xenófobos y la opinión pública negativa sobre la migración nicaragüense. En ambos países, el Estado puede permitirse mantener una política de no intervención con respecto a las personas migrantes y sus familias. Finalmente, este análisis muestra la continua importancia del Estado para preparar el escenario para la inclusión o exclusión a los servicios sociales y la importancia de la alternativa de mercado como una estrategia de supervivencia para las personas migrantes y sus familias.

\section{Nota}

La investigación de Caitlin Fouratt para este proyecto fue apoyada en parte por el Departamento de Antropología de la Universidad de California, Irvine, a través de una Wenner-Gren Dissertation Fieldwork Grant y una beca del Institute of International Education Graduate Fellowship for International Study. Koen Voorend agradece el apoyo brindado por el Instituto Internacional de Estudios Sociales de la Universidad Erasmus de Rotterdam y el programa Settling into Motion de la ZEIT Stiftung, del cual fue becario entre 2012 y 2015. Ambos autores agradecen a Diego Sánchez-Ancochea por una lectura crítica y su retroalimentación extremadamente útil a una versión anterior del manuscrito. También agradecemos a María Villalobos por su rigurosidad y entusiasmo en el trabajo de traducción y edición.

\section{Bibliografía}

Agustín, Laura. “Forget Victimisation: Granting Agency to Migrants". Development. 46/3 (2003): 30-36.

Asamblea Legislativa de la República de Costa Rica. Ley General de Migración y Extranjería N. ${ }^{\circ}$ 8764. San José: Asamblea Legislativa de la República de Costa Rica, 2009.

Babb, Florence. "From Cooperatives to Microenterprises: The Neoliberal Turn in Postrevolutionary Nicaragua". The Third Wave of Modernization in Latin America: Cultural Perspectives on Neoliberalism. Ed. Lynne Phillips, 1998. 109-22.

Banco Central de Nicaragua (BCN). Informe de Remesas Familiares. II Trimestre 2015 (División Económica). (2015). Recuperado de http://www.bcn.gob.ni/publicaciones/periodici$\mathrm{dad} /$ trimestral/remesas/Remesas_2.pdf

Banting, Keith. "Looking in Three Directions: Migration and the European Welfare State in Comparative Perspective". Eds. Michael Bommes y Andrew Geddes, 2000. 13-33.

Baumeister, Eduardo, Edgar Fernández, and Guillermo Acuña. Estudio Sobre Las Migraciones Regionales de Los Nicaragüenses. Ciudad de Guatemala: Editorial de Ciencias Sociales, 2008.

Baumeister, Eduardo. "Migración internacional y desarrollo en Nicaragua," Poblacion y Desarrollo. Santiago, Chile: CEPAL, 2006.

Bonilla, Roger. "Seguro social y usos de servicios de salud entre personas nicaragüenses en Costa Rica". El mito roto. Inmigración y emigración en Costa Rica. Ed. Carlos Sandoval., San José: EUCR, 2007. 145-160.

Castañeda, Irma. "A Necessary Effort: The Construction of a Binational Immigration Policy for Nicaraguan Immigrants in Costa Rica". Independent Study Project (ISP) Collection. Paper 1424. 2012. Recuperado de http://digitalcollections.sit.edu/isp_collection/1424 
Castillo, Jacqueline. “Características de la Atención de los Extranjeros en los Servicios de Salud de la Caja Costarricense de Seguro Social 1997-2002". Presidencia Ejecutiva, Dirección Actuarial y de Planificación Económica. San José: CCSS, 2003.

Castles, Stephen, Hein de Haas y Mark J. Miller. The Age of Migration: International Population Movements in the Modern World. Palgrave Macmillan, 2013.

Comisión Económica para América Latina y el Caribe (CEPAL). CEPALSTAT 2015. Santiago de Chile: CEPAL, 2015.

De Genova, Nicholas. "Migrant 'Illegality' and Deportability in Everyday Life", Annual Review of Anthropology. 31 (2002): 419-447.

Dobles, I., G. Vargas y K. Amador. Inmigración: Psicología, identidades y políticas públicas. La experiencia nicaragüense y colombiana en Costa Rica. San José: Editorial UCR, 2013.

Faist, Thomas. "Immigration, integration and the ethnicization of politics". European Journal of Political Research. 25 (1994): 439-459.

Faist, Thomas. "Immigration, integration and the welfare state". The Challenge of Diversity Integration and Pluralism in Societies of Immigration. Eds. A. Heller, R. Bauböck y A. Zolberg. Aldershot: Avebury, 1996. 227-258.

Favell, Adrian. "The nation-centered perspective". Dialogues on Migration Policy. Eds. M. Giugni y F. Passy. Oxford: Lexington Books, 2006. 45-56.

Fischer, Andrew. "Towards Genuine Universalism within Contemporary Development Policy". IDS Bulletin. 41/1 (2010): 36-44.

Fouratt, Caitlin E. "Presences and Absences: The Reconfigurations of Kinship and Care in Nicaraguan Transnational Families". Tesis doctoral. University of California, Irvine, 2014a.

Fouratt, Caitlin E. “'Those who come to do harm': The Framings of Immigration Problems in Costa Rican Immigration Law". International Migration Review. 48/1 (2014b): 144-180.

Fouratt, Caitlin E. "Temporary Measures: The Production of Illegality in Costa Rican Immigration Law". PoLAR: Political and Legal Anthropology Review. 39/1 (2016): 144-160.

Goldade, Kathryn. "'Health Is Hard Here' or 'Health for All'? The Politics of Blame, Gender, and Health Care for Undocumented Nicaraguan Immigrants in Costa Rica". Medical Anthropology Quarterly. 23/4 (2009): 483-503.

Gonzales, Roberto y Chavez, Leo. “'Awakening to a Nightmare': Abjectivity and Illegality in the Lives of Undocumented 1.5-Generation Latino Immigrants in the United States". Current Anthropology. 53/3 (2013): 255-281.

González, Heydi y Horbaty, Gabriela. “Nicaragua y Costa Rica: migrantes enfrentan percepciones y políticas migratorias". Conferencia Migración Intrafronteriza en América Central, Perspectivas Regionales. San José. Recuperado de http://ccp.ucr.ac.cr/noticias/migraif/ pdf/horbaty.pdf

Grabel, Ilene. "Remittances, Political Economy and Economic Development. DevISSues Migration in a Globalizing World". Development ISSues. 11/2 (2009): 16-19.

Guiraudon, Virginie y Lahav, Gallya. "A Reappraisal of the State Sovereignty Debate. The Case of Migration Control". Comparative Political Studies. 33/2 (2000): 163-195.

Hernández, Ester y Coutin, Susan Bibler. "Remitting Subjects: Migrants, Money and States". Economy and Society. 35 (2006): 198.

Hjerm, Mikael. "Integration into the social democratic welfare state”. Social Indicators Research. 70/2 (2005): 117-138. 
Hollifield, James. "Immigration and the politics of rights. The French case in comparative perspective". Immigration and Welfare. Challenging the borders of the welfare state. Eds. M. Bommes y A. Geddes. London y New York: Routledge, 2000. 108-131.

IDESPO, UNFPA y Foro Permanente sobre Población Migrante. Memoria Final, Mesa Redonda: La Población Migrante en Costa Rica y su Tratamiento en los Medios de Comunicación, (2000).

Instituto Nacional de Estadística y Censos (INEC). IIX Censo Nacional de Población, Costa Rica 1984. San José: INEC, 1984.

Instituto Nacional de Estadística y Censos (INEC). X Censo Nacional de Población y VI de Vivienda 2011 Resultados Generales. San José: INEC, 2011.

Instituto Nacional de Estadística y Censos de Argentina (INDEC). Censo Nacional de Población, Hogares y Viviendas 2010. Buenos Aires: INDEC, 2010.

Instituto Nacional de Estadísticas de Chile (INE). XVIII Censo Nacional de Población y VII de Vivienda o Censo de Población y Vivienda 2012. Santiago de Chile: INE, 2012.

Jacobson, David. Rights Across Borders. Immigration and the Decline of Citizenship. Baltimore: Johns Hopkins University Press, 1996.

Joppke, Christian. "Transformation of Citizenship: Status, Rights, Identity". Citizenship Studies. 11 (2007): 37-48. Doi 10.1080/13621020601099831

Kapur, Devesh. "Remittances: The New Development Mantra?" United Nations Conference on Trade and Development (UNCTAD), 2003. http://g24.org/wp-content/ uploads/2014/03/Kapur-1.pdf

Kalir, Barak. "Moving Subjects, Stagnant Paradigms: Can the "Mobilities Paradigm" Transcend Methodological Nationalism?". Journal of Ethnic and Migration Studies. 39/2 (2013): 311-327.

Kron, Stefanie. "Gestión migratoria en Norte y Centroamérica: Manifestaciones y contestaciones". Anuario de Estudios Centroamericanos. 37 (2011): 53-85.

Kyle, David y Siracusa, Christina. "Seeing the State Like a Migrant. Why so Many NonCriminals Break Immigration Laws". Illicit Flows and Criminal Things: States, Borders, and the Other Side of Globalization. Eds. W. van Schendel y I. Abraham. Bloomington, IN: Indiana University Press, 2005. 153-176.

López, Mauricio. The Incorporation of Nicaraguan Temporary Migrants into Costa Rica's Healthcare System: An Opportunity for Social Equity?, 2012. Recuperado de http://scholar.uwindsor. ca/etd/502/

Mahler, Sarah. American Dreaming: Immigrant Life on the Margins. Princeton, NJ: Princeton University Press, 1995.

Martínez Franzoni, Juliana y Sánchez-Ancochea, Diego. Good jobs and social services: How Costa Rica achieved the elusive double incorporation. Hampshire: Palgrave Macmillan, 2013.

Martínez Franzoni, Juliana y Voorend, Koen. "The Limits of Family and Community Care: Challenges for Public Policy in Nicaragua". Global Variations in the Political and Social Economy of Care. Worlds Apart. Eds. S. Razavi y S. Staab. London: Routledge/UNRISD, 2012a. 122-140.

Martínez Franzoni, Juliana y Voorend, Koen. "Who Cares in Nicaragua? A Care Regime in an Exclusionary Social Policy Context". Development and Change. 42/4 (2011): 995-1022.

Martínez Franzoni, Juliana y Voorend, Koen. Veinticinco años de cuidados en Nicaragua. Poco estado, poco mercado, mucho trabajo no remunerado. San José: Guayacán, 2012b. 
McIlwaine, Cathy. "Legal Latins: Creating Webs and Practices of Immigration Status among Latin American Migrants in London". Journal of Ethnic and Migration Studies. 41/3 (2015): 493-511.

Miles, Ann. From Cuenca to Queens: An Anthropological Story of Transnational Migration. Austin, TX: University of Texas Press, 2010.

Mkandawire, Thandika. "Targeting and Universalism in Poverty Reduction". Social Policy and Development Programme Paper N. ${ }^{\circ}$ 23. Geneva: UNRISD, (2005). Recuperado de http:// www.unrisd.org/unrisd/website/document.nsf/ab82a6805797760f80256b4f005da1ab/ 955fb8a594eea0b0c12570ff00493eaa/\$FILE/mkandatarget.pdf

Mojica, Francisco. Acciones del Estado costarricense para enfrentar demanda de servicios de salud, educación y vivienda de población nicaragüense en Costa Rica. Heredia: Instituto de Estudios Sociales en Población (IDESPO), Universidad Nacional, 2003.

Monge-González, Ricardo, Oswald Céspedes-Torres y Juan Carlos Vargas-Aguilar. SouthSouth Remittances: The Costa Rica Nicaragua Corridor. San José, Costa Rica: InterAmerican Development Bank, 2011. Recuperado de http://publications.iadb.org/ handle/11319/5430

Morales, Abelardo y Castro, Carlos. Migración, Empleo y Pobreza. San José: FLACSO Costa Rica, 2006.

Morissens, Ann. "Migration, welfare states and the incorporation of migrants in different welfare regimes". UNRISD Flagship Report on Poverty. Geneva: UNRISD, 2008. Recuperado de http://www.unrisd.org/80256B3C005BCCF9/(httpAuxPages)/8BDE3DF39F415843 C1257A5D0056587F/\$file/MorrissensWeb.pdf

Naciones Unidas. "International Migration Wallchart". Department of Economic and Social Affairs, Population Division, 2015. Recuperado de http://www.un.org/ en/development/desa/population/migration/publications/wallchart/docs/ MigrationWallChart2015.pdf

Nowalski, Jorge y Barahona, Manuel. Asimetrías Económicas, Sociales y Políticas en Costa Rica: Hacia una Calidad de Vida Digna. San José: PNUD, Centro Internacional para el Desarrollo Humano (CIDH), 2003.

Nowalski, Jorge. Asimetrías económicas, laborales y sociales en Centroamérica: Desafíos y oportunidades. San José: FLACSO, 2002.

Noy, Shiri y Voorend, Koen. "Social Rights and Migrant Realities: Migration Policy Reform and Migrants' Access to Health Care in Costa Rica, Argentina, and Chile". Journal of International Migration and Integration. 17/2 (2016): 605-629.

Pribble, Jennifer "The Politics of Building Municipal Institutional Effectiveness in Chile". Latin American Politics and Society. 57/3 (2015): 100-121.

Programa de Naciones Unidas para el Desarrollo (PNUD). Human Development Report 2015. Washington: PNUD, 2015.

Sainsbury, Diane. "Immigrants' social rights in comparative perspective: welfare regimes, forms of immigration and immigration policy regimes". Journal of European Social Policy. 16/3 (2006): 229-244.

Sandoval, Carlos. "Contestar la hostilidad antiinmigrante en Costa Rica. Un proyecto de Ciencias Sociales públicas en curso". Entreverse. Teoría y metodología práctica de las fuentes orales. Ed. M. Lona. Bilbao: Universidad del País Vasco / Euskal Herriko Unibertsitatea, Argitalpen Zerbitzua, (2012): 217-240. 
Sandoval, Carlos. “Contested Discourses on National Identity: Representing Nicaraguan Immigration to Costa Rica". Bulletin of Latin American Research. 23 (2004): 434-445.

Sandoval, Carlos. El Mito Roto: Inmigración y Emigración en Costa Rica. San José: Editorial Universidad de Costa Rica, 2007.

Sassen, Saskia. Losing control? Sovereignty in the age of globalization. New York, NY: Columbia University Press, 1996.

Sharma, Aradhana. "Introduction: Rethinking Theories of the State in an Age of Globalization". The Anthropology of the State: A Reader. Eds. Aradhana Sharma y Akhil Gupta. Oxford: John Wiley \& Sons, 2009: 1-41.

Solís, Pedro. "El fenómeno de la xenofobia en Costa Rica desde una perspectiva histórica". Revista de Filosofía de La Universidad de Costa Rica XLVII. 120-121 (2010): 92-97.

Soysal, Yasemin. Limits of Citizenship. Migrants and Postnational Membership in Europe. London: The University of Chicago Press, 1994.

Spesny-Dos Santos, Sara. "Undeserving mothers? Shifting rationalities in the maternal healthcare of undocumented Nicaraguan migrants in Costa Rica". Anthropology \& Medicine. 22/2 (2015): 191-201.

Stoll, David. El Norte or Bust! How Migration Fever and Microcredit Produced a Financial Crash in a Latin American Town. Lanham, MD: Rowman and Littlefield Publishers, 2012.

Thomas, Felicity y Gideon, Jasmine, eds. Migration, Health and Inequality. London, UK: Zed Books, 2013.

Van Hooren, Franca. "Caring migrants in European welfare regimes: the policies and practice of migrant labor filling the gaps in social care". Tesis doctoral. European University Institute, 2011.

Voorend, Koen y Robles Rivera, Francisco. Migrando en la crisis: La fuerza de trabajo inmigrante en la economía costarricense. San José: OIM, MTSS, Gobierno de Canadá, 2011.

Voorend, Koen y Venegas, Karla. “Tras de cuernos, palos. Percepciones sobre Costa Rica como imán de bienestar en la crisis del seguro social". Revista de Ciencias Sociales. 145/III (2014): 13-33.

Voorend, Koen. ¿Universal o Excluyente? Derechos sociales y control migratorio interno en Costa Rica. Colección Red de Posgrados en Ciencias Sociales. 32. Buenos Aires: CLACSO, 2013.

Voorend, Koen. "A Welfare Magnet in the South? Migration and Social Policy in Costa Rica". Tesis doctoral. La Haya, Holanda. International Institute of Social Studies, Erasmus University Rotterdam, 2016.

Walters, William, Galina Cornelisse, Nicholas De Genova y Nathalie Peutz. The Deportation Regime: Sovereignty, Space, and the Freedom of Movement. Duke University Press, 2010.

Willen, Sarah. “Toward a Critical Phenomenology of 'Illegality': State, Power, Criminalization, and Abjectivity among Undocumented Migrant Workers in Tel Aviv, Israel". International Migration. 43(2007): 8-38.

Caitlin E. Fouratt. Estadounidense. Ph. D. en Antropología Cultural de la Universidad de California, Irvine. Ph. D. en Estudios Latinoamericanos de la Universidad de Cambridge. Profesora asistente de Estudios Internacionales y Directora 
del Programa de Estudios de Migración Global de la Universidad Estatal de California en Long Beach (CSULB).

Contacto: Caitlin.Fouratt@csulb.edu

ORCID: 0000-0003-1331-3738

Koen Voorend. Holandés. Ph. D. y M. A. en Estudios de Desarrollo del Instituto Internacional de Estudios Sociales de la Universidad Erasmus de Rotterdam, en la Haya, Holanda. Además, M. A. en Estudios de Economía Internacional, de la Universidad de Maastricht, Holanda. Investigador del Instituto de Investigaciones Sociales de la Universidad de Costa Rica y profesor asociado de la Escuela de Ciencias de la Comunicación Colectiva de esa misma institución.

Contacto: koen.voorend@ucr.ac.cr

ORCID: 0000-0002-2955-6243 
